\title{
Transmission Dynamics of Highly Pathogenic Avian Influenza Virus A(H5Nx) Clade 2.3.4.4, North America, 2014-2015
}

\author{
Dong-Hun Lee, ${ }^{1}$ Mia Kim Torchetti, Joseph Hicks, Mary Lea Killian, \\ Justin Bahl, Mary Pantin-Jackwood, David E. Swayne
}

\begin{abstract}
Eurasia highly pathogenic avian influenza virus (HPAIV) H5 clade 2.3.4.4 emerged in North America at the end of 2014 and caused outbreaks affecting $>50$ million poultry in the United States before eradication in June 2015. We investigated the underlying ecologic and epidemiologic processes associated with this viral spread by performing a comparative genomic study using 268 full-length genome sequences and data from outbreak investigations. Reassortant HPAIV H5N2 circulated in wild birds along the Pacific flyway before several spillover events transmitting the virus to poultry farms. Our analysis suggests that $\geq 3$ separate introductions of HPAIV H5N2 into Midwest states occurred during March-June 2015; transmission to Midwest poultry farms from Pacific wild birds occurred $\approx 1.7-2.4$ months before detection. Once established in poultry, the virus rapidly spread between turkey and chicken farms in neighboring states. Enhanced biosecurity is required to prevent the introduction and dissemination of HPAIV across the poultry industry.
\end{abstract}

$\mathrm{H}$ ighly pathogenic avian influenza virus (HPAIV) A(H5N1) emerged in 1996 in Guangdong, China (A/goose/Guangdong/1/1996 [Gs/GD]), and has since caused outbreaks in poultry, infections in wild birds, and often fatal clinical cases in humans in $>80$ countries (1). In late autumn 2014, Gs/GD H5N8 clade 2.3.4.4 was reported in East Asia, Europe, and the west coast of North America $(2,3)$. The timing and direction of this virus's dissemination, which coincided with waterfowl migration patterns, together with phylogenetic and geospatial data $(3,4)$ support the hypothesis that Gs/GD H5N8 clade 2.3.4.4 was introduced into North America through the Beringian Crucible via intercontinental movement of migratory waterfowl $(5,6)$.

Author affiliations: US Department of Agriculture, Athens, Georgia, USA (D.-H. Lee, M. Pantin-Jackwood, D.E. Swayne); US

Department of Agriculture, Ames, lowa, USA (M.K. Torchetti, M.L. Killian); University of Texas School of Public Health, Houston, Texas, USA (J. Hicks, J. Bahl)

DOI: https://doi.org/10.3201/eid2410.171891
In November and December 2014, novel reassortant $\mathrm{H} 5 \mathrm{~N} 1, \mathrm{H} 5 \mathrm{~N} 2$, and $\mathrm{H} 5 \mathrm{~N} 8$ viruses were detected in wild waterfowl along the Pacific flyway $(2,7)$. Reassortant H5N2 virus was identified as the causative agent of influenza outbreaks in poultry farms in British Columbia, Canada, and among wild waterfowl in the northwestern United States (Video, https://wwwnc.cdc.gov/EID/article/24/10/17-1891-V1.htm) (8). This virus subsequently was the predominant strain during HPAIV outbreaks among poultry in the United States in 2015, particularly during March-June $(9,10)$, and was detected in wild birds migrating along the Pacific, Central, and Mississippi flyways $(11,12)$. The last reported virus detection related to the outbreak in the United States was in June 2015 from a Canada goose in Michigan. Despite increased surveillance efforts in the United States, HPAIV was rarely detected in wild bird populations during the latter half of 2015 and 2016 (13). In 2015, the virus was detected just 2 times by real-time reverse transcription PCR in mallards, once in July (from bird banding efforts in Utah) and once in November (from a hunter harvest in Oregon) (14). In 2016, H5N2 virus clade 2.3.4.4 was detected in 2 mallards sampled in Alaska and Montana, providing evidence for low-level maintenance of this virus in wild birds in northwestern North America $(15,16)$. Despite disagreement about the role of flyways in limiting viral spread among wild birds $(17,18)$, the rapid spatial diffusion and transmission of HPAIV in wild and domestic birds highlight the need to further investigate the processes involved in viral emergence and spread.

We sequenced and analyzed the full-length genome sequences of $249 \mathrm{H} 5 \mathrm{~N} 2$ and 19 H5N8 HPAIVs collected during the 2014-2015 outbreaks in the United States. Viruses came from 32 wild birds, 7 raptors, 14 backyard poultry farms, and 196 commercial poultry sites. We used a molecular epidemiologic approach involving genome sequences and outbreak information to determine the evolution and spread patterns of these viruses.

${ }^{1}$ Current affiliation: University of Connecticut, Storrs, Connecticut, USA. 


\section{Materials and Methods}

\section{Genome Sequencing}

The National Animal Health Laboratory Network conducts PCR testing for avian influenza in the United States, and per title 9, Code of Federal Regulations, nonnegative samples are forwarded to the National Veterinary Services Laboratories (Ames, Iowa, USA) for confirmation testing and genome sequencing. In December 2014, interagency wild bird surveillance started including testing for the HPAIV Gs/GD lineage in wild birds in the Pacific flyway, and by summer 2015, surveillance was further expanded to include testing for this virus in all flyways (19). In our study, we included all available wild bird $(\mathrm{n}=32)$ and raptor $(n=7)$ viruses from these surveillance efforts and, for poultry, just 1 virus from each affected site with available samples ( $\mathrm{n}=210 ; 14 / 21$ affected backyard sites, 196/211 affected commercial flocks) (20).

We extracted viral RNA from 249 H5N2-positive and 19 H5N8-positive oral or cloacal swab samples using MagMAX Viral RNA Isolation Kit (Ambion, Foster City, CA, USA). We synthesized complementary DNA and amplified all 8 segments by reverse transcription PCR using SuperScript III (Invitrogen, Carlsbad, CA, USA) (21). We conducted genome sequencing using the Ion Torrent PGM (Life Technologies, Waltham, MA, USA) or MiSeq (Illumina, San Diego, CA, USA) platforms as previously described $(7,16)$. We assembled genome sequences using SeqMan NGen version 4 (http://www.dnastar.com/t-nextgen-seqman-ngen.aspx). We deposited nucleotide sequences in GenBank (online Technical Appendix Table 5, https:// wwwnc.cdc.gov/EID/article/24/10/17-1891-Techapp1.pdf).

\section{Maximum-Likelihood Phylogenetic Analysis of US HPAIV H5N2}

Of the $265 \mathrm{H} 5 \mathrm{~N} 2$ sequences analyzed, we retrieved the 16 viruses from Canada from the GISAID EpiFlu database (http://platform.gisaid.org) and sequenced the 249 viruses from the United States. In all, 32 viruses were from wild waterfowl in 10 states (Alaska, Idaho, Kansas, Kentucky, Michigan, Missouri, Montana, Oregon, Washington, Wyoming); 7 viruses were from captive and wild raptors in 5 states (Idaho, Minnesota, Missouri, Washington, Wisconsin); and 210 viruses were from backyard and commercial poultry farms in 13 states (Arkansas, Idaho, Iowa, Kansas, Minnesota, Missouri, Montana, Nebraska, North Dakota, Oregon, South Dakota, Washington, Wisconsin). Data from Minnesota (1 backyard farm, 99 commercial poultry farms, 1 wild bird) and Iowa (69 commercial poultry farms), where most commercial poultry were affected, predominated in this sample.

To demonstrate the phylogenetic organization of the HPAIV outbreak, we built a maximum-likelihood phylogenetic tree of the concatenated genome (all 8 genome segments) with RAxML version 8.0.0 (22) using default parameters and a general time-reversible model with gamma-distributed rate variation among sites. We divided the $265 \mathrm{H} 5 \mathrm{~N} 2$ isolates into subgroups of related clusters by their bootstrap value $(>70 \%)$ on maximum-likelihood phylogenetic analysis (23). To assess relatedness support, we performed rapid bootstrapping, with bootstrap convergence criterion yielding 1,000 bootstrap iterations. We illustrated the time series of outbreaks by subgroup and state using Tableau (https://www.tableau.com/).

\section{Median-Joining Network Analysis}

We concatenated all 8 genome segments of each virus isolate to generate a single alignment. We used these alignments to construct a phylogenetic network using the median-joining method implemented in program NETWORK version 5.0 (http://www.fluxus-engineering.com/sharenet rn.htm) with epsilon set to 1 (24).

\section{Ancestral State Reconstruction of Geographic Location and Host Type}

To investigate virus transmission between host types over large spatial scales, we reconstructed the virus transmission history between states geographically using an ancestral state reconstruction approach with a Bayesian stochastic search variable selection to determine the most probable spatial and ecologic transmission history. For all phylogeographic analyses, we used an uncorrelated log-normal distribution relaxed-clock method with a Hasegawa, Kishino, and Yano nucleotide substitution model and Bayesian skyride coalescent prior.

Using a globally derived dataset $(n=127$ taxa) of HPAIV hemagglutinin (HA) sequences from Asia, Europe, and North America, we tested whether the HPAIV H5 outbreak in North America resulted from a single virus introduction or multiple virus introductions into the bird population of North America. We then developed a more refined model to estimate viral diffusion and transmission between wild and domestic populations and assess the most likely route of spread. We incorporated HPAIV HA sequences from the US and Canada 2014-2015 outbreaks (11) into our discrete phylogenetic model. In this model, we defined geographic region and host type as discrete nominal categories. We categorized geographic region of virus collection by migratory flyway (Pacific, Central, Mississippi) and host type as chicken, turkey, wild bird, or backyard poultry. We estimated ancestral state transition rate and model parameters from a set of 5,000 empirical trees simulated from HPAIV H5 HA gene data collected throughout the outbreaks. For the discrete ancestral state model, we used a nonreversible continuous-time Markov chain model to estimate geographic and host transitions among wild and 
domestic birds (25). We used Bayesian stochastic search variable selection to identify important transitions using a binary indicator $(I)(18,26,27)$, enabling the calculation of Bayes factor with SPREAD version 1.0.6 (28). A transition was considered important when $I$ was $>0.5$ and Bayes factor was $>4.0(18,26)$. We used the last 500 trees from each posterior distribution to construct heat maps representing the average number of transitions per month (online Technical Appendix).

\section{Results}

The highly pathogenic phenotype of viruses sequenced in this study were confirmed by presence of the polybasic amino acid motif at the HA cleavage site and through experimental infection of chickens by intravenous inoculation (online Technical Appendix). Analysis of globally circulating Gs/GD-lineage $\mathrm{H} 5 \mathrm{Nx}$ clade 2.3.4.4 viruses showed a widespread distribution and confirmed that the lineage causing the outbreak in North America probably resulted from a single introduction (online Technical Appendix Table 2, Figure 1). During December 2014-March 2015, H5N2 was detected in poultry farms of British Columbia and in wild waterfowl and backyard poultry of states along the Pacific flyway (Figure 1). Subsequently, during March-June 2015, H5N2 predominated in poultry outbreaks in the Midwest.

We generated a maximum-likelihood phylogenetic tree and median-joining phylogenetic network of HPAIV H5N2 using 265 concatenated full-genome sequences (249 from the United States, 16 from Canada) to investigate the relatedness of isolates (Figure 2; online Technical Appendix
Figure 2). The H5N2 viruses formed 2 major genetic groups, group 1 and group 2 (includes subgroups 2a, 2b, 2c, $2 \mathrm{~d}, 2 \mathrm{e}$, and 2 nonclustered [2nc]), with maximum-likelihood phylogeny bootstrap proportions $>75 \%$. Group 1 contains 73 viruses from 11 US states and 2 Canada provinces across the Pacific (Alaska, Idaho, Montana, Oregon, and Washington, USA; British Columbia), Central (Kansas, South Dakota, and Wyoming, USA), and Mississippi (Arkansas, Minnesota, and Missouri, USA; Ontario, Canada) flyways (online Technical Appendix Figures 3, 4). Group 2 predominantly contained viruses isolated from poultry from states along the Mississippi flyway: $2 \mathrm{a}(\mathrm{n}=39$; Iowa, Minnesota, Missouri, Wisconsin); $2 \mathrm{~b}(\mathrm{n}=35$; Minnesota); $2 \mathrm{c}(\mathrm{n}=11$; Iowa, Minnesota); $2 \mathrm{~d}(\mathrm{n}=4$; Wisconsin); and 2e ( $\mathrm{n}=81$; Iowa, Minnesota; Nebraska, South Dakota in Central flyway). Twenty-two $2 \mathrm{nc}$ viruses were detected in 6 states along the Central (North Dakota, South Dakota) and Mississippi (Kentucky, Michigan, Minnesota, Wisconsin) flyways.

Both group 1 and 2 viruses were found in wild birds and gallinaceous poultry (Figure 2; online Technical Appendix Figure 3). Wild birds infected with group 2 viruses were only infected with subgroup 2 nc viruses. Group 1 viruses were recovered from all host types represented (28 wild birds, 5 raptors, 11 backyard poultry, 14 commercial poultry [ 1 chicken, 13 turkeys]). Subgroups $2 \mathrm{c}$ and $2 \mathrm{~d}$ were found only in turkeys and had limited geographic spread. The remaining subgroups affected several hosts. Subgroup 2 nc viruses were isolated from 6 wild birds, 13 commercial turkey sites, and 3 commercial chicken sites. Subgroup 2a was found in 2 backyard sites, 36 commercial turkey sites,

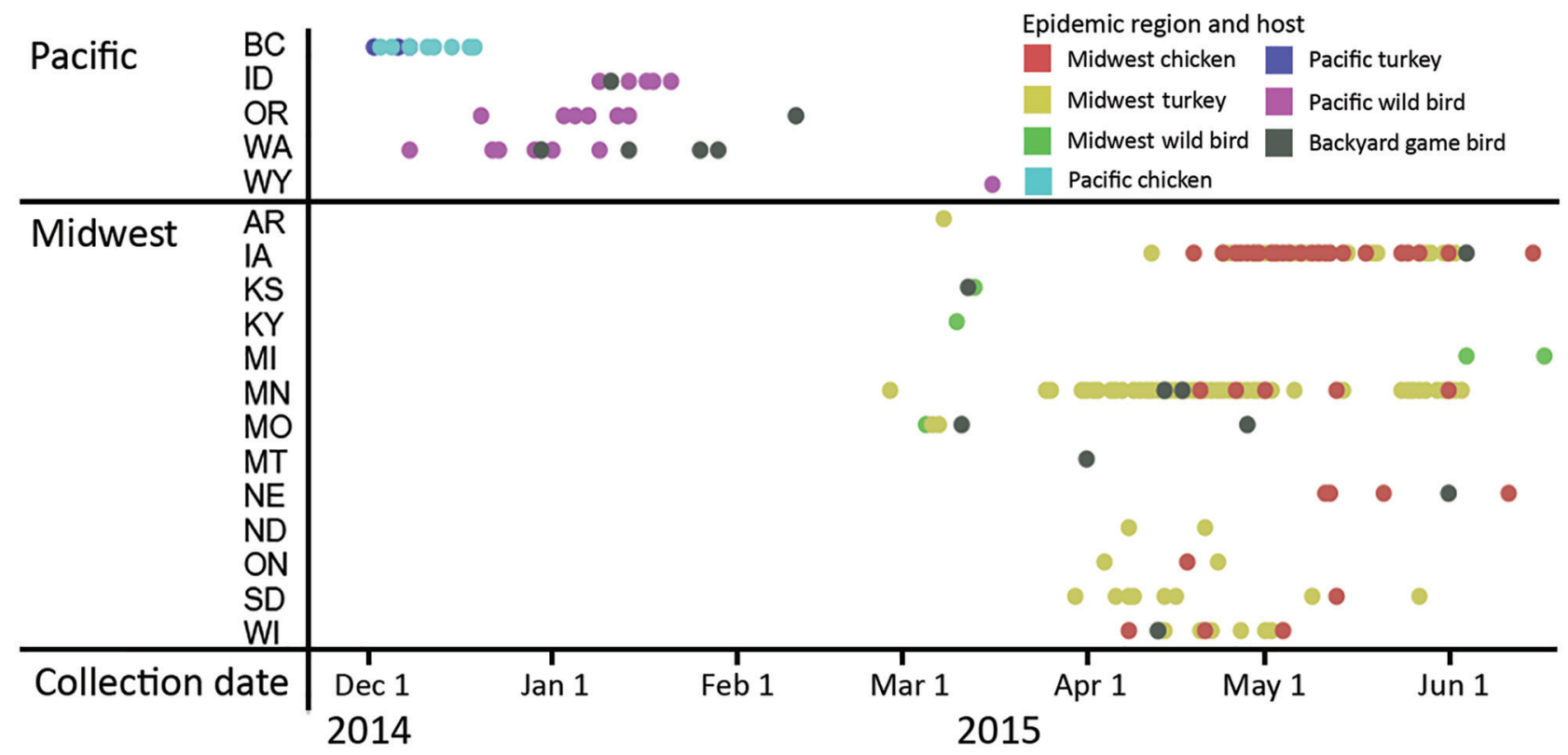

Figure 1. Time series of reassortant highly pathogenic avian influenza virus $A(H 5 N 2)$ distribution, by US state and Canada province, December 2014-June 2015. Virus region and host are indicated. BC, British Columbia, Canada; ON, Ontario, Canada. 


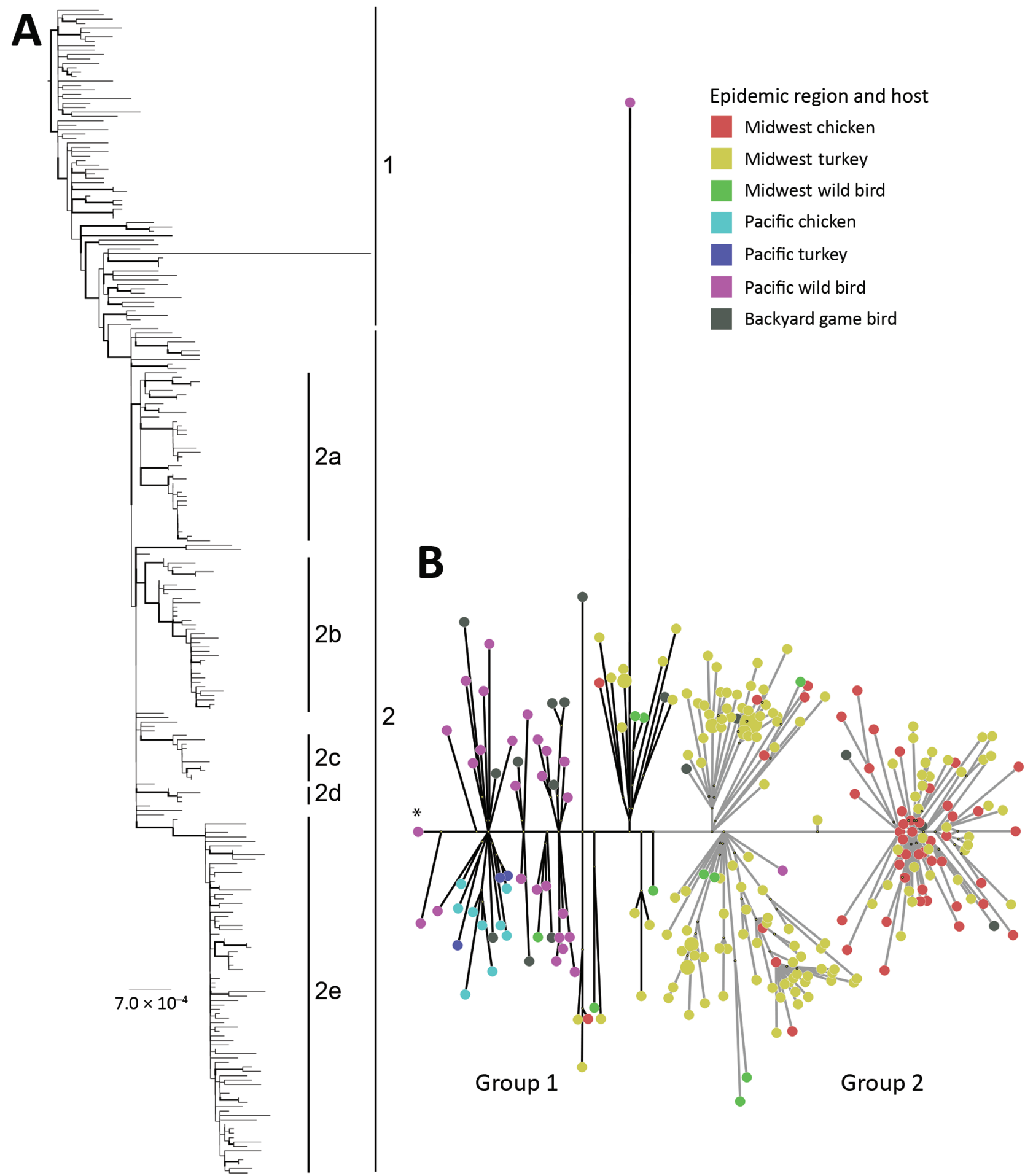

Figure 2. Genetic characterization of reassortant highly pathogenic avian influenza virus $\mathrm{A}(\mathrm{H} 5 \mathrm{~N} 2)$ clade 2.3.4.4, North America, 2014-2015. A) Maximum-likelihood phylogeny of concatenated complete genome sequences. Labels indicate genetic subgroups. Scale bar indicates nucleotide substitutions per site. The full version of the phylogenic tree is available in online Technical Appendix Figure 2 (https://wwwnc.cdc.gov/EID/article/24/10/17-1891-Techapp1.pdf). B) Median-joining phylogenetic network constructed by using concatenated complete genome sequences. This network includes the most parsimonious trees linking the sequences. Each unique sequence is represented by a circle sized relative to its frequency in the dataset. Virus region and host are indicated. *US index H5N2 virus (A/Northern_pintail/Washington/40964/2014). 
and 1 commercial chicken site. Subgroup $2 \mathrm{~b}$ predominantly affected commercial turkey sites $(\mathrm{n}=32)$ and 3 commercial chicken flocks; subgroup $2 \mathrm{e}$ was recovered from 2 backyard, 36 commercial turkey, and 42 commercial chicken sites and 1 game bird flock. Genetic clustering of subgroups $2 \mathrm{a}, 2 \mathrm{~b}$, and 2e in maximum-likelihood analysis and the close genetic relatedness of Midwest poultry isolates in network analysis provide strong evidence for extensive interfarm transmission (Figure 2; online Technical Appendix Figure 2).

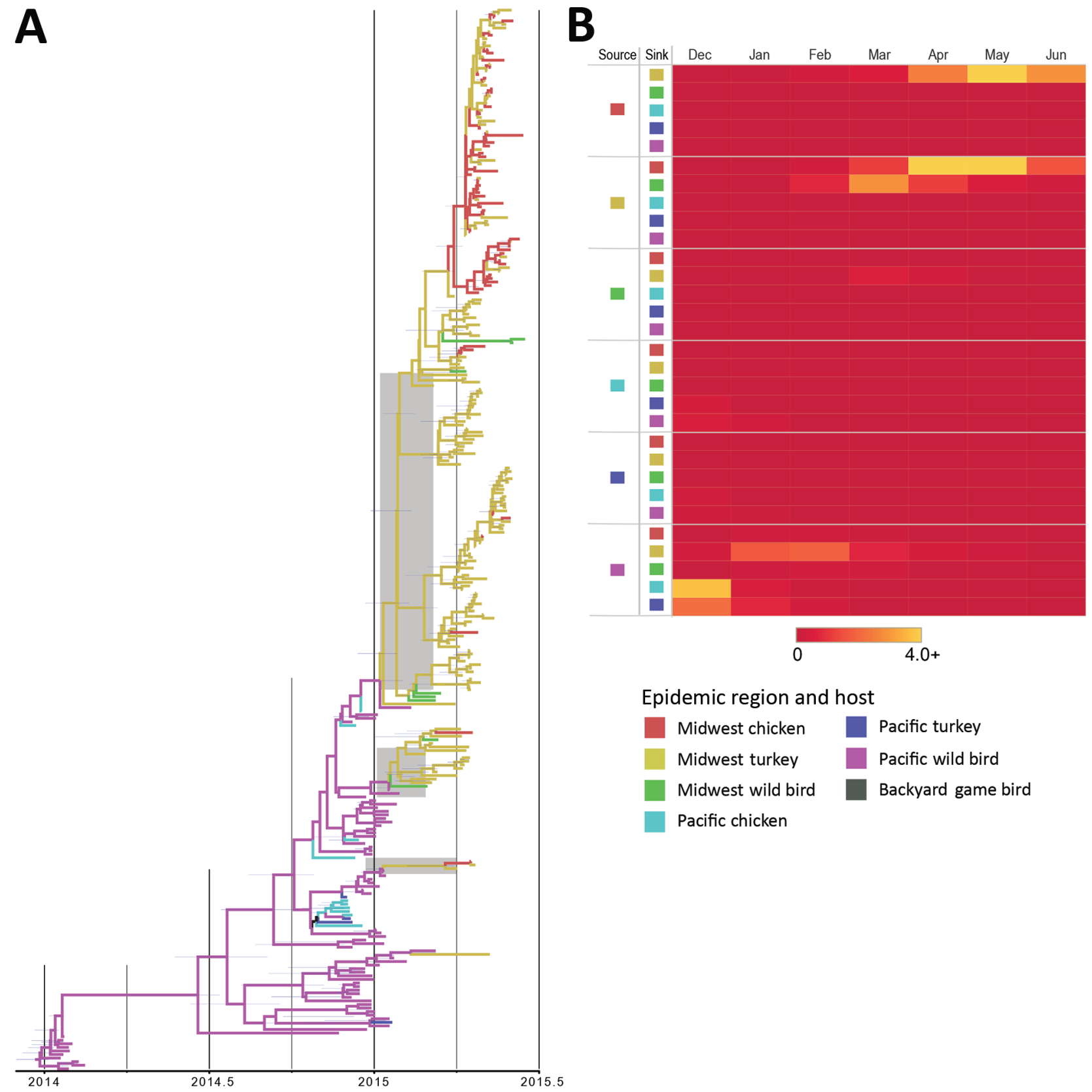

Figure 3. Phylogeographic reconstruction of source-sink dynamics of highly pathogenic avian influenza virus $A(H 5 N 2)$ outbreak, United States, 2014-2015. A) Phylogenetic tree of hemagglutinin gene of H5N2 isolates. The geographic region and host type were defined in the model as discrete nominal character states, and the number of state transitions at tree nodes was counted. The character states included in the phylogenetic model (Midwest chicken, Midwest turkey, Midwest wild bird, Pacific chicken, Pacific turkey, and Pacific wild bird) are indicated. Black nodes and branches represent an ancestral reconstruction that is highly uncertain, sharing equal probability between Pacific wild bird and Pacific turkey. The shaded boxes represent the time between the introduction of the virus into Midwest poultry populations and the first detection of the virus within the population. B) Heat map showing source-sink dynamics and average number of transitions per location per year (0-4.0). 
Our phylogenetic analysis suggests that the outbreak in the Midwest was initiated through multiple independent HPAIV H5N2 introductions with group 1 viruses of wild bird origin (Figures 2,3). To formally test the role of various host populations and elucidate the most likely route for viral spread in the United States, we integrated host type (wild birds, domestic chickens and turkeys, backyard poultry) into our geographic model. Our source-sink and phylogenetic network analyses suggest that the virus detected in the Midwest shares a common ancestor with the viruses detected in the Pacific flyway 1.7-2.4 months before the first detection in Midwest poultry facilities (Figure 3; online Technical Appendix Figure 5). Undetected infected hosts also could have migrated from the Pacific Coast through the Midwest, depositing infectious material on the US landscape, leading to the outbreaks in Midwest poultry populations. The virus subsequently rapidly transmitted between commercial turkey and chicken farms. The rapid rate of transmission suggests that underlying epidemiologic factors were driving the spread within and between farm systems.

Bayesian simulation results showed that turkey farms and chicken farms were equally supported as the source of infection of domestic flocks after establishment of the virus in Midwest US farms (Table). Although the discrete state transition rate from chicken farms to turkey farms was higher, this difference is likely an artifact of the substantially larger flocks found in chicken farms, which predominantly use layer houses. Our analysis showed high rates of transmission between turkey and chicken farms in the Midwest, probably confounding control efforts and contributing to the overall extent of the outbreak (Figure 3, panel B). No support exists for viral spread from Midwest wild birds to Midwest commercial farms, suggesting that this epidemiologic pathway likely did not play a role in the spread of the outbreak after the initial introduction into the Midwest (Table), which has further been supported by epidemiologic investigations (29). In addition, a transition from Midwest turkey to wild birds is supported by a high Bayes factor (4798.91) and posterior probability (0.999), suggesting HPAIV spillback from domestic poultry to wild birds at a low transition rate (Table).

We identified 14 common substitutions across the entire genome of HPAIV H5N2 when comparing with US index virus A/northern pintail/WA/40964/2014 (H5N2). These substitutions include 10 nonsynonymous substitutions in group 1 and 2 viruses (L386V and V649I in polymerase basic 2; L8F, N130T, and S157P in HA; R253K, E368K, and V412A in neuraminidase; Q78R in matrix 2; I176T in nonstructural protein 1) and 4 nonsynonymous substitutions in group 2 viruses ( $215 \mathrm{~K}$ in polymerase basic 1, A337V in polymerase acidic, $\mathrm{N} 60 \mathrm{H}$ in nuclear export protein, K217T in nonstructural protein 1) (online Technical Appendix Table 3).

\section{Discussion}

Phylogenetic reconstruction of source-sink dynamics supports multiple independent introductions of HPAIV H5N8 into the United States during late 2014 from wild birds. Despite the frequent detection of HPAIV H5 in wild birds of the Pacific flyway up to February 2015 (30), only 2 commercial poultry and 1 backyard farm flocks became infected with HPAIV H5N8 and 7 backyard poultry flocks with HPAIV H5N2 in states along the Pacific flyway. No HPAIV H5N2 infections were found at commercial poultry sites in states along the Pacific flyway (31). In contrast with infrequent events in states along the Pacific flyway, 213 H5N2 events in commercial and backyard poultry were reported during March-June 2015 in the Midwest. Our analysis demonstrates extensive interfarm transmission of virus subgroups $2 \mathrm{a}, 2 \mathrm{~b}$, and $2 \mathrm{e}$ but not of group 1 viruses, which could also infect wild birds, suggesting a change in the epidemiologic processes driving viral spread. Although a national level-structured surveillance effort was not initiated until July 2015 (19), H5N2 detections were far less frequent in the Midwest than in the Pacific flyway, suggesting few H5N2-infected wild waterfowl were in the Central and Mississippi flyways during the outbreak period $(32,33)$. Nonetheless, detection of H5N2 viruses from wild birds in the Midwest in early 2015 and our phylogenetic analysis suggest that the HPAIV H5N2 moved from the Pacific flyway to the Mississippi and Central flyways as early as January or February 2015, with subsequent interfarm transmission in and between states of the Midwest.

When performing the source-sink phylogenetic analysis, we made assumptions regarding sampling and population structure, which should be considered when interpreting results. For instance, sampling in this analysis is most likely biased toward commercial poultry because of the nature of HPAIV reporting. Oversampling of a specific population might lead to overestimation of that group as a sink to viral migration (34); however, a secondary simulation in which viral host characteristics were continuously randomized to observe the influence of sampling heterogeneity (35) revealed that sampling does not appear to bias the ancestral reconstruction in this data. Also, in the model, we included the complete random population mixing assumption, even though a structured coalescent approach might have helped limit bias introduced from ecologic barriers that structure wild and domestic bird populations; many of the HPAIV sequences from poultry hosts used in our study represented a single farm. No data were available regarding the size of farms, number of animals infected on those farms, or number of farms affected, all of which might further bias spatial diffusion parameter estimates in a structured coalescent analysis. 
Table. Well-supported discrete trait viral transitions among chicken, turkey, and wild bird populations during highly pathogenic avian influenza virus H5 outbreak, Midwest and Pacific regions, USA, 2014-2015*

\begin{tabular}{|c|c|c|c|c|}
\hline Transition from & Transition to & Bayes factor & Posterior probability & Mean transition rate \\
\hline Midwest chicken & Midwest turkey & $38,421.1688$ & 1.0 & 5.0917 \\
\hline Midwest turkey & Midwest chicken & $38,421.1688$ & 1.0 & 1.8376 \\
\hline Midwest turkey & Midwest wild bird & $4,798.9103$ & 0.9991 & 0.8344 \\
\hline Pacific wild bird & Pacific chicken & 464.3334 & 0.9909 & 0.8478 \\
\hline Pacific wild bird & Midwest turkey & 227.2091 & 0.9816 & 0.8557 \\
\hline Pacific wild bird & Pacific turkey & 201.2141 & 0.9792 & 0.5687 \\
\hline
\end{tabular}

The hypothesis that HPAIV H5N2 was introduced into the Midwest through wild birds rather than poultry production channels is supported by epidemiologic evidence; during February 27-April 20, 2015, H5N2 virus was detected 17 times across 5 states and 16 counties in different hosts (wild bird, raptor, backyard flocks, turkey flocks), and epidemiologic links could not be found between Pacific Coast and Midwest farms for any virus subgroup. The widespread detection of the HPAIV H5 lineage in healthy wild birds (30), subclinical infection with high virus shedding, and transmission among mallard ducks experimentally infected with HPAIV H5N2 (36) support the hypothesis of HPAIV H5 dissemination to multiple states through wild waterfowl over a short period during wild aquatic bird migrations. For the outbreak in the Midwest (February-June 2015), events (infections with viruses of groups 1 and 2nc) detected early during the outbreak (February-April 2015) probably represent independent introductions, followed by limited secondary spread, and events (infections with viruses of subgroups $2 \mathrm{a}-\mathrm{e}$ ) detected later during the outbreak (April-June 2015) were largely caused by extensive interfarm transmission. Previous estimates of basic reproductive number and viral migration among host types in domestic and wild birds support our findings that HPAIV H5N2 rapidly spread between poultry facilities in the Midwest after the initial introduction of a virus of wild bird origin (37). Grear et al. showed that the H5N2 and H5N8 HPAIV outbreak did not encounter sufficient transmission barriers to prevent persistence when introduced to wild or domestic birds (37). Consistent with our data, Grear et al. concluded that once the HPAIV H5N2 entered the poultry production system in the Midwest, transmission was driven through poultry production-related mechanisms (37). That conclusion was based on evidence of a close phylogenetic distance among sequences from poultry facilities, relatively infrequent cross-species transmission, and a high estimated proportion of virus diversity in addition to the lack of detection of this lineage in reservoir hosts when using other surveillance data. Our Bayesian simulation also supports the high probability of 2-way transmission between poultry and wild bird populations.

The epidemiology of the HPAIV H5 detections and pathobiologic features suggest that the early $\mathrm{H} 5 \mathrm{~N} 8$ and H5N2 group 1 viruses detected in the United States were highly adapted to waterfowl and poorly adapted to chickens and turkeys $(36,38-40)$. Index wild bird viruses [A/ gyrfalcon/Washington/40188-6/2014 (H5N8), A/northern pintail/Washington/40964/2014 (H5N2)] required a high mean bird infectious dose of $50 \%\left(\mathrm{BID}_{50} ; 10^{5.7} \mathrm{EID}_{50}\right)$ to infect chickens; directly inoculated and in-contact exposed survivors did not seroconvert (38). Increased virus adaptation to chickens and turkeys, specifically poultry, was observed among the H5N2 group 2 viruses and not the H5N2 group 1 viruses $(39,40)$. In chickens, the $\mathrm{BID}_{50}$ of $\mathrm{H} 5 \mathrm{~N} 2$ group 2 viruses for poultry $\left(10^{3.2-3.6} \mathrm{EID}_{50}\right)$ was lower than that of group 1 viruses for poultry $\left(10^{5.1} \mathrm{EID}_{50}\right)$ and index wild birds $\left(10^{5.7} \mathrm{EID}_{50}\right)$.

Examination of mutational frequencies and patterns showed common mutations among H5N2 subgroup 2a-e viruses fixed in the population during circulation in poultry. In particular, substitutions in the nucleoprotein amino acid 105 (M105V, M105I) were identified among H5N2 group 2 viruses from the United States and a virus isolate from a chicken in British Columbia (11) and has been suggested as a determinant for virus adaptation from ducks to chickens (41). Consistent with our previous study (39), we identified common substitutions (R215K polymerase basic 1, A337V polymerase acidic, $\mathrm{N} 60 \mathrm{H}$ nuclear export protein, K217T nonstructural protein 1) in $\mathrm{H} 5 \mathrm{~N} 2$ group 2 viruses that increased infectivity and pathogenicity in chickens in comparison with group 1 viruses. In addition, we found substitution S157P at an antigenic site of the HA protein, which might affect the immunogenicity profile of the virus (42).

In summary, we analyzed the transmission dynamics of Asia-origin HPAIV H5 in the United States. The H5N8 virus came from East Asia, entered North America during the fall 2014 migration season (7), and spread rapidly along the wild bird flyways in the United States starting in December 2014. In the Pacific flyway, Eurasia H5N8 virus circulated in wild birds and disseminated to backyard and commercial poultry farms largely by point-source introductions; a single detection occurred in a backyard flock in Indiana outside the Pacific states. Furthermore, influenza A genome segments of the Eurasia H5N8 virus mixed with segments of the North America low pathogenicity avian influenza viruses, creating new reassortant HPAIVs H5N1, $\mathrm{H} 5 \mathrm{~N} 2$, and H5N8. For the reassortant H5N2 virus in the Midwest, our results strongly support introduction from the 
Pacific flyway early in 2015 , with $\geq 3$ initial independent introductions and late events involving extensive secondary spread between poultry farms. These $\mathrm{H} 5 \mathrm{~N} 8$ and $\mathrm{H} 5 \mathrm{~N} 2$ viruses cause substantial illness and death in poultry but have, thus far, not been implicated in human infection. Mammalian studies in mice and ferrets suggest low public health risk $(43,44)$.

During 2016-2017, HPAIV H5N8 clade 2.3.4.4 group B (Gochang-like) reemerged and caused outbreaks in wild birds and domestic poultry across Europe, Asia, and Africa $(45,46)$. Enhanced biosecurity is required to prevent the introduction and dissemination of HPAIVs across the poultry industry; the role that human activity can play in viral spread via fomites should not be underestimated. Continued surveillance, virus characterization, and infectivity studies remain invaluable to monitoring the spread and evolution of these H5 viruses; such efforts could further the design of improved prevention strategies. Additional research is needed to decipher the potential mechanisms of virus introduction into poultry systems.

\section{Acknowledgments}

We thank the Veterinary Services and Center of Epidemiology and Animal Health staffs (especially Philip D. Riggs) of the Animal and Plant Health Inspection Service, US Department of Agriculture, for their contribution to data visualization, and we thank the Diagnostic Virology Laboratory avian diagnostic team of the National Veterinary Services Laboratories. We thank the authors of the research we cited and staff of laboratories contributing sequences to the GISAID's EpiFlu database, on which this research is based. A detailed list of acknowledgments is provided in online Technical Appendix Table 4.

J.B. and J.H. are partially supported by the National Institutes of Health Centers for Excellence in Influenza Research and Surveillance (contract no. HHSN272201400006C).

\section{About the Author}

Dr. Lee is a postdoctoral researcher at the Southeast Poultry Research Laboratory of the Agricultural Research Service, US Department of Agriculture, Athens, Georgia, USA. His research interests include molecular epidemiology and host-pathogen interactions of avian influenza viruses.

\section{References}

1. Lee DH, Bertran K, Kwon JH, Swayne DE. Evolution, global spread, and pathogenicity of highly pathogenic avian influenza H5Nx clade 2.3.4.4. J Vet Sci. 2017;18(S1):269-80. http://dx.doi.org/10.4142/jvs.2017.18.S1.269

2. Ip HS, Torchetti MK, Crespo R, Kohrs P, DeBruyn P, Mansfield $\mathrm{KG}$, et al. Novel Eurasian highly pathogenic avian influenza A H5 viruses in wild birds, Washington, USA, 2014. Emerg Infect Dis. 2015;21:886-90. http://dx.doi.org/10.3201/eid2105.142020
3. Global Consortium for H5N8 and Related Influenza Viruses. Role for migratory wild birds in the global spread of avian influenza H5N8. Science. 2016;354:213-7. http://dx.doi.org/ 10.1126/science.aaf8852

4. Verhagen JH, Herfst S, Fouchier RAM. How a virus travels the world. Science. 2015;347:616-7. http://dx.doi.org/10.1126/ science.aaa6724

5. Lee DH, Torchetti MK, Winker K, Ip HS, Song CS, Swayne DE. Intercontinental spread of Asian-Origin H5N8 to North America through Beringia by migratory birds. J Virol. 2015;89:6521-4. http://dx.doi.org/10.1128/JVI.00728-15

6. Ramey AM, Reeves AB, TeSlaa JL, Nashold S, Donnelly T, Bahl J, et al. Evidence for common ancestry among viruses isolated from wild birds in Beringia and highly pathogenic intercontinental reassortant $\mathrm{H} 5 \mathrm{~N} 1$ and $\mathrm{H} 5 \mathrm{~N} 2$ influenza A viruses. Infect Genet Evol. 2016;40:176-85. http://dx.doi.org/10.1016/j.meegid.2016.02.035

7. Lee DH, Bahl J, Torchetti MK, Killian ML, Ip HS, DeLiberto TJ, et al. Highly pathogenic avian influenza viruses and generation of novel reassortants, United States, 2014-2015. Emerg Infect Dis. 2016;22:1283-5. http://dx.doi.org/10.3201/eid2207.160048

8. Pasick J, Berhane Y, Joseph T, Bowes V, Hisanaga T, Handel K, et al. Reassortant highly pathogenic influenza $\mathrm{A}$ H5N2 virus containing gene segments related to Eurasian H5N8 in British Columbia, Canada, 2014. Sci Rep. 2015;5:9484. http://dx.doi.org/ 10.1038/srep09484

9. US Department of Agriculture. HPAI 2014-2015 infected premises. 2016 Jun 8 [cited 2017 Nov 15]. https://www.aphis.usda.gov/ animal_health/animal_dis_spec/poultry/downloads/hpai-positivepremises-2014-2015.pdf

10. US Department of Agriculture. HPAI 2014/15 confirmed detections. 2015 [cited 2017 Nov 15]. https://www.aphis.usda.gov/ aphis/ourfocus/animalhealth/animal-disease-information/ avian-influenza-disease/sa_detections_by_states/hpai-20142015-confirmed-detections

11. Xu W, Berhane Y, Dubé C, Liang B, Pasick J, VanDomselaar G, et al. Epidemiological and evolutionary inference of the transmission network of the 2014 highly pathogenic avian influenza H5N2 outbreak in British Columbia, Canada. Sci Rep. 2016;6:30858. http://dx.doi.org/10.1038/srep30858

12. US Department of Agriculture. Wild bird positive highly pathogenic avian influenza cases in the United States. 2015 Sep 4 [cited 2017 Nov 15]. https://www.aphis.usda.gov/wildlife_damage/ downloads/WILD\%20BIRD\%20POSITIVE\%20HIGHLY\%20 PATHOGENIC\%20AVIAN\%20INFLUENZA\%20CASES\%20 IN\%20THE\%20UNITED\%20STATES.pdf

13. Krauss S, Stallknecht DE, Slemons RD, Bowman AS, Poulson RL, Nolting JM, et al. The enigma of the apparent disappearance of Eurasian highly pathogenic H5 clade 2.3.4.4 influenza A viruses in North American waterfowl. Proc Natl Acad Sci U S A. 2016;113:9033-8. http://dx.doi.org/10.1073/pnas.1608853113

14. US Department of Agriculture. Wild bird positive highly pathogenic avian influenza cases in the United States. 2016 Jun 30 [cited 2017 Nov 15]. https://www.aphis.usda.gov/animal_health/ downloads/animal_diseases/ai/uspositivecases.pdf

15. US Department of Agriculture. Wild bird highly pathogenic avian influenza cases in the United States. 2017 Jul 7 [cited 2017 Nov 15]. https://www.aphis.usda.gov/animal_health/downloads/ animal_diseases/ai/uspositivecases17.pdf

16. Lee DH, Torchetti MK, Killian ML, DeLiberto TJ, Swayne DE. Reoccurrence of avian influenza A(H5N2) virus clade 2.3.4.4 in wild birds, Alaska, USA, 2016. Emerg Infect Dis. 2017;23:365-7. http://dx.doi.org/10.3201/eid2302.161616

17. Lam TT, Ip HS, Ghedin E, Wentworth DE, Halpin RA, Stockwell TB, et al. Migratory flyway and geographical distance are barriers to the gene flow of influenza virus among North American birds. Ecol Lett. 2012;15:24-33. http://dx.doi.org/ 10.1111/j.1461-0248.2011.01703.x 
18. Bahl J, Krauss S, Kühnert D, Fourment M, Raven G, Pryor SP, et al. Influenza A virus migration and persistence in North American wild birds. PLoS Pathog. 2013;9:e1003570. http://dx.doi.org/10.1371/journal.ppat.1003570

19. US Department of Agriculture. Surveillance plan for highly pathogenic avian influenza in waterfowl in the United States, 2015 Jun [cited 2017 Nov 15] https://www.aphis.usda.gov/animal_health/ downloads/animal_diseases/ai/2015-hpai-surveillance-plan.pdf

20. US Department of Agriculture. HPAI 2014-2015 infected premises. 2016 Jun 8 [cited 2017 Nov 15] https://www.aphis.usda.gov/ animal_health/animal_dis_spec/poultry/downloads/hpai-positivepremises-2014-2015.pdf

21. Bowman AS, Sreevatsan S, Killian ML, Page SL, Nelson SW, Nolting JM, et al. Molecular evidence for interspecies transmission of $\mathrm{H} 3 \mathrm{~N} 2 \mathrm{pM} / \mathrm{H} 3 \mathrm{~N} 2 \mathrm{v}$ influenza A viruses at an Ohio agricultural fair, July 2012. Emerg Microbes Infect. 2012;1:e33. http://dx.doi.org/10.1038/emi.2012.33

22. Stamatakis A. RAxML version 8: a tool for phylogenetic analysis and post-analysis of large phylogenies. Bioinformatics. 2014;30:1312-3. http://dx.doi.org/10.1093/bioinformatics/btu033

23. Hillis DM, Bull JJ. An empirical test of bootstrapping as a method for assessing confidence in phylogenetic analysis. Syst Biol. 1993;42:182-92. http://dx.doi.org/10.1093/sysbio/42.2.182

24. Bandelt HJ, Forster P, Röhl A. Median-joining networks for inferring intraspecific phylogenies. Mol Biol Evol. 1999;16:37-48. http://dx.doi.org/10.1093/oxfordjournals.molbev.a026036

25. Minin VN, Suchard MA. Counting labeled transitions in continuous-time Markov models of evolution. J Math Biol. 2008;56:391-412. http://dx.doi.org/10.1007/s00285-007-0120-8

26. Bahl J, Pham TT, Hill NJ, Hussein IT, Ma EJ, Easterday BC, et al. Ecosystem interactions underlie the spread of avian influenza A viruses with pandemic potential. PLoS Pathog. 2016;12:e1005620. http://dx.doi.org/10.1371/journal.ppat. 1005620

27. Lemey P, Rambaut A, Drummond AJ, Suchard MA. Bayesian phylogeography finds its roots. PLOS Comput Biol. 2009;5:e1000520. http://dx.doi.org/10.1371/journal.pcbi.1000520

28. Bielejec F, Rambaut A, Suchard MA, Lemey P. SPREAD: spatial phylogenetic reconstruction of evolutionary dynamics. Bioinformatics. 2011;27:2910-2. http://dx.doi.org/10.1093/ bioinformatics/btr481

29. US Department of Agriculture. Epidemiologic and other analyses of HPAI-affected poultry flocks: September 9, 2015 report. 2015 Sep 9 [cited 2017 Nov 15]. https://www.aphis.usda.gov/ animal_health/animal_dis_spec/poultry/downloads/EpidemiologicAnalysis-Sept-2015.pdf

30. Bevins SN, Dusek RJ, White CL, Gidlewski T, Bodenstein B, Mansfield KG, et al. Widespread detection of highly pathogenic H5 influenza viruses in wild birds from the Pacific flyway of the United States. Sci Rep. 2016;6:28980. http://dx.doi.org/10.1038/srep28980

31. US Department of Agriculture. Final report for the 2014-2015 outbreak of highly pathogenic avian influenza (HPAI) in the United States. 2016 Aug 11 [cited 2017 Nov 15]. https://www.aphis.usda. gov/animal_health/emergency_management/downloads/hpai/ 2015-hpai-final-report.pdf

32. Jennelle CS, Carstensen M, Hildebrand EC, Cornicelli L, Wolf P, Grear DA, et al. Surveillance for highly pathogenic avian influenza virus in wild birds during outbreaks in domestic poultry, Minnesota, 2015. Emerg Infect Dis. 2016;22:1278-82. http://dx.doi.org/10.3201/eid2207.152032

33. Jennelle CS, Carstensen M, Hildebrand EC, Wolf PC, Grear DA, Ip HS, et al. Surveillance for highly pathogenic avian influenza in wild turkeys (Meleagris gallopavo) of Minnesota, USA during 2015 outbreaks in domestic poultry. J Wildl Dis. 2017;53:616-20. http://dx.doi.org/10.7589/2016-09-205

34. Frost SD, Pybus OG, Gog JR, Viboud C, Bonhoeffer S, Bedford T. Eight challenges in phylodynamic inference.
Epidemics. 2015;10:88-92. http://dx.doi.org/10.1016/ j.epidem.2014.09.001

35. Edwards CJ, Suchard MA, Lemey P, Welch JJ, Barnes I, Fulton TL, et al. Ancient hybridization and an Irish origin for the modern polar bear matriline. Curr Biol. 2011;21:1251-8. http://dx.doi.org/ 10.1016/j.cub.2011.05.058

36. Pantin-Jackwood MJ, Costa-Hurtado M, Shepherd E, DeJesus E, Smith D, Spackman E, et al. Pathogenicity and transmission of H5 and $\mathrm{H} 7$ highly pathogenic avian influenza viruses in mallards. J Virol. 2016;90:9967-82. http://dx.doi.org/10.1128/JVI.01165-16

37. Grear DA, Hall JS, Dusek RJ, Ip HS. Inferring epidemiologic dynamics from viral evolution: 2014-2015 Eurasian/North American highly pathogenic avian influenza viruses exceed transmission threshold, $R_{0}=1$, in wild birds and poultry in North America. Evol Appl. 2018;11:547-57. http://dx.doi.org/10.1111/ eva. 12576

38. Bertran K, Swayne DE, Pantin-Jackwood MJ, Kapczynski DR, Spackman E, Suarez DL. Lack of chicken adaptation of newly emergent Eurasian H5N8 and reassortant H5N2 high pathogenicity avian influenza viruses in the U.S. is consistent with restricted poultry outbreaks in the Pacific flyway during 2014-2015. Virology. 2016;494:190-7. http://dx.doi.org/10.1016/j.virol.2016.04.019

39. DeJesus E, Costa-Hurtado M, Smith D, Lee DH, Spackman E, Kapczynski DR, et al. Changes in adaptation of H5N2 highly pathogenic avian influenza $\mathrm{H} 5$ clade 2.3.4.4 viruses in chickens and mallards. Virology. 2016;499:52-64. http://dx.doi.org/ 10.1016/j.virol.2016.08.036

40. Spackman E, Pantin-Jackwood MJ, Kapczynski DR, Swayne DE, Suarez DL. H5N2 highly pathogenic avian influenza viruses from the US 2014-2015 outbreak have an unusually long pre-clinical period in turkeys. BMC Vet Res. 2016;12:260. http://dx.doi.org/ 10.1186/s12917-016-0890-6

41. Tada T, Suzuki K, Sakurai Y, Kubo M, Okada H, Itoh T, et al. NP body domain and PB2 contribute to increased virulence of $\mathrm{H} 5 \mathrm{~N} 1$ highly pathogenic avian influenza viruses in chickens. J Virol. 2011;85:1834-46. http://dx.doi.org/10.1128/JVI.01648-10

42. Chen MW, Liao HY, Huang Y, Jan JT, Huang CC, Ren CT, et al. Broadly neutralizing DNA vaccine with specific mutation alters the antigenicity and sugar-binding activities of influenza hemagglutinin. Proc Natl Acad Sci U S A. 2011;108:3510-5. http://dx.doi.org/10.1073/pnas.1019744108

43. Pulit-Penaloza JA, Sun X, Creager HM, Zeng H, Belser JA, Maines TR, et al. Pathogenesis and transmission of novel highly pathogenic avian influenza $\mathrm{H} 5 \mathrm{~N} 2$ and $\mathrm{H} 5 \mathrm{~N} 8$ viruses in ferrets and mice. J Virol. 2015;89:10286-93. http://dx.doi.org/10.1128/ JVI.01438-15

44. Kaplan BS, Russier M, Jeevan T, Marathe B, Govorkova EA, Russell CJ, et al. Novel highly pathogenic avian A(H5N2) and A(H5N8) influenza viruses of clade 2.3.4.4 from North America have limited capacity for replication and transmission in mammals. mSphere. 2016;1:e00003-16. http://dx.doi.org/10.1128/mSphere.00003-16

45. Pohlmann A, Starick E, Harder T, Grund C, Höper D, Globig A, et al. Outbreaks among wild birds and domestic poultry caused by reassorted influenza A(H5N8) clade 2.3.4.4 viruses, Germany, 2016. Emerg Infect Dis. 2017;23:633-6. http://dx.doi.org/10.3201/ eid2304.161949

46. Lee DH, Sharshov K, Swayne DE, Kurskaya O, Sobolev I, Kabilov M, et al. Novel reassortant clade 2.3.4.4 avian influenza A(H5N8) virus in wild aquatic birds, Russia, 2016. Emerg Infect Dis. 2017;23:359-60. http://dx.doi.org/10.3201/eid2302.161252

Address for correspondence: David E. Swayne, Southeast Poultry Research Laboratory, US Department of Agriculture, Agricultural Research Service, 934 College Station Rd, Athens, GA 30605, USA; email: david.swayne@ars.usda.gov 